Tesis. Año 12, 11(12), 181-194

\title{
La música como parte de la construcción ficcional en Aquú está la música
}

\author{
Ilmar Piero Montaldo Acosta \\ pmontaldo@outlook.com
}

\section{Resumen $^{1}$}

La música ha inspirado a la literatura y la literatura ha inspirado a la música. Es más, la música ha estado ligada a la poesía pues en sus inicios esta se cantaba. Ambas se han nutrido para generar nuevas obras de arte. Como toda creación artística, despierta multiplicidad de sentidos, sobre todo cuando se encuentran como referencias, textos ligados con el mundo de la música. El fin del siguiente artículo es explicar y reflexionar sobra la poética de Aqui está la música en base a las conexiones entre música y literatura a través de la identificación de los elementos intertextuales y paratextuales, y lo interactivo como elemento lúdico. Palabras clave: Narrativa, intertextualidad, paratextualidad, interactividad, música.

\begin{abstract}
Music has always inspired literature and literature has always inspired music. Even more since music and poetry have been tied together from their beginnings, given the fact that poetry was originally sung. Both have nurtured each other in order to create new works of art. As any artistic creation, it wakes up all of the senses, especially when references are found amongst texts related to the music's world. This article explains and reflects on the poetics of Aqui está la música basing itself on the connections between music and literature through the identification of intertextual and paratextual elements as well as looking at its interactive nature, a playful element.
\end{abstract}

Keywords: Narrative, intertextuality, paratextuality, interactivity, music. 


\title{
La música como parte de la construcción ficcional en Aquú está la música
}

\section{Introducción}

\begin{abstract}
¿Debo escribir? Excave en sí mismo en busca de una respuesta que venga de lo profundo (...) Una obra de arte es buena cuando surge de la necesidad. Rainer Maria Rilke (2006, pp.10-11).
\end{abstract}

$\mathrm{El}$ acto creativo es un proceso del pensamiento, el cual muchas veces asociamos a algo que brota de la nada o que es pura intuición, y a veces, que solo unos cuantos escogidos son los llamados a poder tenerlo. Pero cuando un producto creativo nace, detrás de este hay una reflexión y una intención. Cuando un creador tiene historias dando vueltas en su cabeza, las posibles ansiedades que pueden surgir, se tranquilizan cuando se van gestando.

En la música, las diferentes tonalidades, melodías, armonías, ritmos y silencios, plantean una atmosfera cuya unidad se completará con la letra de la canción. En ella se pueden contar situaciones, sentimientos, turbaciones, fantasías, etc. En las canciones, la voz que interpreta es también una voz narrativa, entendiendo a esta como el personaje narrador de la historia de la canción que se recreará a través del cantante o interprete por medio de una melodía.

Tanto en la música como en la literatura no hay mucha diferencia en el concepto de armado, diseño o creación; es decir, en un disco, se agrupan una cantidad de canciones y se perfila cómo quiere el autor que suene. La mayoría agrupa sus canciones con un mismo estilo musical. Otras veces, el género no es lo que determina un disco, sino puede ser una propuesta personal, una propuesta de autor, en la cual cada canción contará una historia distinta tanto en letra como musicalmente. Lo mismo ocurre con libros de cuentos, donde cada autor podrá darle un sentido y una unidad a lo que quiere plasmar. En el caso de Aquí está la música, hay diferentes historias cuyo hilo conductor o temático se basa en 
lo musical dentro de estas, a través de sus personajes. Un libro de cuentos donde todos los personajes están ligados a la música.

En Aqui está la música, existen tres elementos claves: los personajes están ligados a la música, las historias están situadas en Perú, en diferentes ciudades y, los instrumentos musicales que aparecen son variados, como el piano, el violín, el violonchelo, la guitarra, la armónica, el charango, etc.

Dentro de este hay dos piezas fundamentales para cerrar el concepto de Aqui está la música, los elementos intertextuales forman parte esencial de la narrativa y los elementos paratextuales completaron el concepto del libro con la siguiente premisa: ¿Cómo se logra que el lector pueda tener otra experiencia a parte de la lectura? El juego lúdico que se plantea era el indicado para ello.

\section{Antecedentes de la música como parte de la literatura}

La escritura había puesto por escrito la música de tradición oral para hacerla entrar en otro ciclo cultural.

Pierre Léry (2007, p. 113).

La música ha inspirado a la literatura y la literatura ha inspirado a la música. Es más, la música ha estado ligada a la poesía pues en sus inicios esta se cantaba. Ambas se han nutrido para generar nuevas obras de arte. Como toda creación artística, despiertan multiplicidad de sentidos, sobre todo cuando se encuentran como referencias, textos ligados con el mundo de la música. Un caso interesante de esta relación entre música y literatura es el del premio nobel de literatura 2016, el músico cantautor Bob Dylan quien ha sido influenciado por la literatura a la hora de crear algunas de sus composiciones.

Cuando empecé a escribir mis propias canciones, la jerga del folk era el único vocabulario que conocía, y yo lo usaba.

Pero también tenía algo más. Tenía principios y sensibilidades y una visión informada del mundo. Y los había tenido por un buen tiempo. Lo aprendí todo en la escuela primaria. Don Quijote, Ivanhoe, Robinson Crusoe, Los Viajes de Gulliver, Historia de Dos Ciudades, todo lo demás - lectura típica de la escuela secundaria que te daba una manera de ver la vida, una comprensión de la naturaleza humana y un estándar para medir las cosas. Me valí de todo ello cuando empecé a componer letras. Y los temas de esos libros quedaron insertos en muchas de mis canciones, ya sea de manera consciente o inconsciente. Quería escribir canciones distintas a cualquier cosa que alguien hubiera escuchado, y estos temas eran fundamentales. (Dylan, 2017) 
La música ha despertado el interés de autores que plasmaron en sus obras, personajes o elementos musicales dentro de sus creaciones. Tenemos el caso de Cervantes con El ingenioso Hidalgo don Quijote de la Mancha, donde toda la obra hace referencias musicales ya sea a instrumentos, músicos, canciones, y hasta títulos de libros de autores de la época.

No sé de literato de aquella época que mencione tantos instrumentos musicales como Cervantes: el nombrarlos con 40 voces distintas habla de un melómano confeso e impune. [...] en Cervantes cada mención se asocia a un cantarcillo, un moquete, un romance, un villancico, una copla, una endecha, un soneto. (Araníbar, 2015, pp. 38-39).

Es decir, lo musical y lo intertextual ligado a la música forma parte de la literatura desde siempre. Los músicos de Bremen de los hermanos Grimm, o los cuentos que escribió E.T.A Hoffman, músico y escritor. En la segunda mitad del siglo pasado, Cabrera Infante escribió Tres tristes tigres, y Cortázar, amante de la música, escribió su célebre cuento "El perseguidor" donde el narrador es un crítico musical que va en busca del músico saxofonista de Jazz, Johnny Carter.

Y un buen día descubrí el jazz y eso no es una novedad para ustedes porque saben bien que el jazz aparece como tema en muchas cosas que he escrito, desde "El perseguidor" hasta largos capítulos de Rayuela y otros textos donde está en el centro de la cosa. (Cortázar, 2013, p.139)

Pero algo interesante en Cortázar es su propuesta intertextual en Rayuela, tanto así que, años después se editó el libro-disco con la música que cita Cortázar a lo largo de la novela.

Publicado en diciembre de 1999 y agotadas sus tres mil copias en mayo de 2000, el libro-disco "Jazzuela. Julio Cortázar y el jazz" fue uno de los proyectos más curiosos y recomendables de los últimos tiempos. Auspiciado por el trabajo de Pilar Peyrats, una entusiasta del jazz y enamorada de la literatura de Julio Cortázar. [...] Espléndido trabajo de escaneado que da pie a presentar el jazz de "Rayuela" en su contexto literario. Es posible así recrear o leer el libro escuchando al mismo tiempo las músicas que se citan en él. (Carrillo, 2001)

Décadas después de salir editado Rayuela, llega una propuesta que incluye no solo un disco, sino que además hace un recorrido por el universo cortazariano. ¿Habría imaginado Cortázar algo así cuando escribió Rayuela, editar su novela junto a un disco?; quiero imaginar que sí.

A fines del siglo pasado tenemos a la novela ;Que viva la música! de Andrés Caicedo, cuyas referencias a letras de canciones y a la música forma parte integral de la propuesta del autor caleño. 
Al realizar un análisis detenido de la novela de Caicedo encontramos alrededor de 70 referencias concretas a la música. En la primera mitad de la novela, en la que el rock es uno de los ejes temáticos, es posible identificar 20 alusiones a este género, de las cuales 12 tienen relación con los Rolling Stones y las restantes con canciones, bandas o intérpretes icónicos de la época. En la segunda mitad del relato, a partir del momento que María del Carmen abandona su última fiesta roquera y cruza la calle para iniciar su periplo en el mundo de la salsa, pudimos identificar más de cuarenta referencias concretas — fragmentos de letras de canciones, títulos y alusiones a intérpretes y músicos- de la salsa. (Echeverry, 2013, p. 63).

Por otro lado, el caso de Chico Buarque, músico brasilero que ha escrito varias novelas desde los años sesenta y donde algunos de los personajes están ligados a la música y donde también utiliza elementos paratextuales como epígrafes al inicio de algunos capítulos donde coloca significados de palabras puestas en otros idiomas, a la vez, alterna con imágenes de documentos escaneados como dedicatorias en páginas de libros, cartas y fotografías, y al final del libro termina un epílogo y notas finales del autor. Todos esos elementos paratextuales envuelven la obra de otras maneras de apreciarla y percibirla, involucrándonos de manera distinta con la historia que se narra.

En el caso del Perú, poetas como José María Eguren, Juan Gonzalo Rose, Luis Hernández, César Calvo o César Miró han ligado su arte con la música de diferentes maneras. Tenemos el caso de Bryce Echenique con La amigdalitis de Tarzán o, La última mudanza de Felipe Carrillo donde las alusiones bolerísticas forman parte de este elemento intertextual que enriquece la poética del autor. (Ferreyra, 1989); también Gregorio Martínez, quien ganó el premio Copé de Oro 2002, con su cuento "Guitarra de Palisandro". Otros autores más contemporáneos como Fernando Carrasco o Ernesto Carlín, han incorporado en sus obras lo musical en personajes, historia o en la atmosfera narrativa. También Gracias totales: Tributo narrativo a Soda Stereo, (Del Pozo, 2017) donde 23 narradores y 4 ilustradores hacen un homenaje ligando los títulos de las canciones con diferentes historias. Podríamos decir que son literatura con bandas sonoras.

Estas novelas - eminentemente visuales- poseen una sonoridad que no reside solamente en la naturaleza de las descripciones (por lo general, muy minuciosas) y la imaginería utilizada, sino que surge además por la evocación que la música citada es capaz de producir en el lector. [...] se podría decir que los escritores han elegido cuidadosamente la música más acorde al ritmo y al tono de sus novelas. La música reviste la trama, le da matices y completa la representación de todo el conjunto. (Navarro, 2003) 
Por lo tanto, lo musical como elemento de discurso y de construcción ficcional ha sido utilizado por diversos autores para recrear nuevos tipos de relaciones transtextuales en sus obras. En ese caso, Aqui está la música, no es ajena a esa tradición.

Aqui está la música es un libro de cuentos, el cual se construye en torno a la música. Por un lado, están los personajes envueltos de una u otra manera en este universo donde lo musical forma parte de las historias. Por otro lado, al inicio del libro se propone un juego con el lector en "Instrucciones para musicalizar los cuentos" y a lo largo de los diferentes cuentos se manifestarán diversos elementos musicales como letras de canciones, nombres de artistas o títulos de canciones.

\section{Polifonía: Intertextualidad, paratextualidad e interactividad}

Si estamos en el concierto de nuestro artista favorito, podremos distinguir el sonido que emite al cantar. Ese sonido nos va dando cuenta de una melodía, es decir, él canta diferentes palabras dándoles una entonación que luego, nosotros reconocemos y percibimos como una canción. Dentro de la estructura de una canción está la parte que se conoce como estribillo o coro, justo en ese momento a esa voz solitaria se le suman otras dos voces cantando la misma letra, y podemos percibir una nueva sensación sonora. Se da una combinación de varias voces donde nuestro oído percibe diferentes timbres vocales, creando una armonía. De ahí el nombre de esa sección musical llamada coro y donde también está lo polifónico. Es más, en ese coro, en esa polifonía no solo pueden estar participando en exclusiva el músico cantante y sus coristas, también podría sumarse el público. Ahí, esa polifonía de voces, aumenta y es participativa. Existe pues, en ese juego de voces del grupo y el público, un sentido, una experiencia que va más allá. Las luces, las pantallas, lo que el artista dice entre las canciones, o sus acotaciones dentro de la misma canción; todo eso formará parte de la experiencia musical donde el artista y el público interactúan y perciben ese momento de una manera muy distinta y especial.

Lo mismo ocurre en la experiencia literaria, donde un escritor envía al lector, a través de su obra, una historia y dentro de esta, se encuentran referencias, citas, alusiones, etc. Elementos que hacen que el lector interactúe de manera dinámica y activa y pueda interpretar y percibir según sus conocimientos.

Intertextualidad, paratextualidad e interactividad, son los elementos que hacen esta "polifonía" y que se encuentran en la obra Aquí está la música. Cabe aclarar que utilizo el término polifonía no como fue utilizado por Bajtin, sino para ejemplificar de manera musical este juego de relaciones que se dan entre intertextualidad, paratextualidad e interactividad con la obra y el lector. Relaciones que se encuentran presentes tanto en los cuentos de Aqui está la música como en el concepto del libro. 
Cuando definimos con una sola palabra un complejo conjunto de situaciones, sentidos o estructuras, corremos el riesgo de limitar o sesgar la mirada con respecto a lo que queremos definir. Por ejemplo, en el caso del concepto de "estética" ocurre lo mismo, pero a la inversa; los filósofos que la estudian siempre van variando, estando a favor o en contra de ciertos conceptos, definiciones y miradas con respecto a ella. (Ranciere, 2011). Un caso similar ocurre con Gennette en su libro Palimpsestos (1989), plantea los nuevos conceptos que tiene sobre la transtextualidad o transcendencia textual del texto y sus cinco elementos que encuentra en esta, como intertextualidad, paratextualidad, entre otras terminologías; pero deja en claro que esos conceptos no están quietos, sino que se van redefiniendo, o que hasta él mismo, con el paso del tiempo, va encontrando mejores términos para nombrar ciertos aspectos del campo de la teoría literaria.

Según Genette (1989), la intertextualidad se define, de manera restrictiva, como: "una relación de copresencia entre dos o más textos, es decir, eidéticamente y frecuentemente, como la presencia efectiva de un texto en otro." (p.10). En ese sentido, Genette remarca que son la cita, el plagio y la alusión, los ingredientes que se encuentran dentro de lo intertextual. La cita es la que se encuentra más notoriamente dentro de Aqui está la música. "Su forma más explícita y literal es la práctica tradicional de la cita (con comillas, con o sin referencia precisa).” (Genette, 1989, p. 10). Es decir, dentro de la intertextualidad como elemento reconocible en la obra, la cita es la que se encontrará dentro de los cuentos que integran Aqui está la música como parte de las historias. Esta se evidencia de tres maneras: citando el nombre de un artista o grupo musical, en títulos de canciones o en los versos de las letras de las canciones, como parte del texto.

Veamos el caso del cuento "Calambrito, Torito y Pepita", donde se muestra a unos niños músicos ambulantes que son atacados por un mozo que atiende en uno de los locales donde suelen ir a tocar. En este cuento, hay dos géneros musicales insertados en el texto, por un lado, los interpretados por nuestros personajes y por el otro, la música que sale del mismo local donde están tocando estos niños y músicos ambulantes. Ellos interpretan temas ligados al folklore nacional y latinoamericano, temas populares y reconocibles para su público de turistas. "El cóndor pasa", "Moliendo café" y "Zambito", son interpretados en diferentes momentos del conflicto que surge entre los protagonistas y el antagonista, que los interrumpe con otro sonido, ya no uno del folklore latinoamericano, sino uno foráneo y en otro idioma; en este caso se cita a Sting y al grupo Queen. Las canciones foráneas, representadas por el género rock y el inglés son las que se verbalizan en el texto. El narrador incluye versos de ambas canciones inglesas. El equipo de sonido es el objeto transmisor de las letras. Por un lado el grito de "Roxanne, you don't have to put on the red light", que obstaculiza 
la interpretación de los niños. Y "Don't stop me now (yes I'm having a good time)", que no solo cumple con el papel de obstruir el desempeño de los niños, sino que además se suma a lo que el personaje de "El Hígado" está sintiendo al estar como amo y dueño del local por algunos minutos.

Este contraste de sonoridades y géneros musicales, es justamente para graficar la diferencia, donde lo latinoamericano sigue siendo avasallado por lo extranjero y donde no se valora nuestra riqueza cultural. Por eso, cuando las citas ingresan en el texto lo hacen a veces como letra de canción, intercalándose entre la música de los niños y la música que sale del equipo de sonido que prende el mozo para fastidiarlos; las citas intertextuales ingresan una después de la otra, como una lucha que se refleja en el enfrentamiento de los niños músicos con el mozo del local.

Si continuamos con la comparación del concierto: las luces, las pantallas que se encuentran detrás de los músicos o a los costados del escenario, lo que dice el artista entre canción y canción como dedicatorias o saludos o lo que dice dentro de esta, que no forma parte explícita de las canciones, sería en el campo literario lo paratextual relacionado con su paratexto. Según Genette (1989) conforman esta categoría lo siguiente:

Título, subtítulo, intertítulos, prefacios, epílogos, advertencias, prólogos, etc.; notas al margen, a pie de página, finales; epígrafes; ilustraciones; fajas, sobrecubiertas, y muchos otros tipos de señales accesorias, autógrafas o alógrafas, que procuran un entorno (variable) al texto y a veces un comentario oficial u oficioso del que el lector más purista y menos tendente a la erudición externa no puede siempre disponer tan fácilmente como lo desearía y lo pretende. (p. 11)

En Aqui está la música, podemos encontrar una nota del autor, dedicatorias, títulos y epígrafes que dialogan con los cuentos; es decir, que no son elementos ajenos o al azar, sino que forman parte de la poética del autor. Y que están establecidos desde que se finaliza el producto artístico, caso contrario se da en un concierto, donde para seguir con las analogías, los saludos se modifican y la interacción entre el cantante y el público varía de un recital a otro.

En cualquier tipo de literatura existen elementos intertextuales y paratextuales, y estos no son exclusivos de la música, es decir que, dentro de otros libros podemos encontrar citas o referencias a otros autores, libros, versos de poemas, alguna referencia cultural, etc. En ese caso, nosotros estamos relacionando Aqui está la música con los elementos ligados a lo musical.

Siguiendo a Levy (2007), el texto impreso es un soporte, el cual permite pasar un mensaje. En este se pueden encontrar modalidades perceptivas del lector; que son en primera instancia la vista y en segundo lugar, el tacto. Ahí 
ya se encuentra un componente interactivo pues "El término 'interactividad' designa generalmente la participación activa del beneficiario de una transacción de información, salvo que esté muerto, nunca es pasivo." (p. 65). Es decir, hay varios tipos de interactividad conforme sea el uso que tenga el usuario, en este caso, el lector con el texto impreso. Este tipo de interactividad es monoparticipativo, es decir que el lector no tiene un diálogo con el emisor o escritor sino que interactúa con la obra. En el caso de Aqui está la música, la percepción del lector irá un paso más allá de lo visual y el tacto, agregará la percepción sonora donde la palabra y la música formarán parte de esta. El libro va más allá de su soporte físico para interactuar con el lector.

Ahora, es curioso que haya sido desde la literatura (expresión sublime del nuevo canal comunicativo) desde donde se hayan dado, desde el comienzo, las inconformidades en relación con el estrecho cerco de la letra y de su soporte, el libro. El libro fue visto por muchos poetas y narradores como un formato que impedía una representación adecuada del mundo. Se configura, entonces, una búsqueda, una auténtica utopía del "más allá del libro".

Al respecto, la hipótesis que manejo es la siguiente: la escritura y su infraestructura técnica, la imprenta, configuraron el dispositivo propio de la comunicación moderna, y la novela se constituyó en su modelo expresivo más logrado. Sin embargo, el ejercicio novelesco estuvo siempre tensionado por una especie de conciencia a medias de que lo narrativo no podía lograr su mejor expresión inmersiva e interactiva bajo las condiciones de un medio que, como el libro, limita dichas funciones a la imaginación de mundos posibles por parte del lector. De ahí se desprendió toda una tradición de experimentación que algunos hacemos corresponder a un momento posmoderno de la literatura, y que tuvo como frontera el propio dispositivo donde se desarrollaba dicha experimentación: el libro. (Rodríguez, 2009, p. 137)

En ese sentido, el elemento paratextual que iniciará este juego propuesto por el autor e invita a que el lector interactúe es "Instrucciones para musicalizar los cuentos" que se presenta como una nota del autor, el cual indica a seguir una pauta de lectura guiada por las músicas que se encuentran a lo largo de los cuentos. Para tal motivo, también se encuentra otro elemento paratextual al final del libro titulado "Soundtrack"; ambos son las partes del libro que logran realizar lo interactivo de la propuesta. Donde el lector tendrá que utilizar otros soportes tecnológicos como una computadora con Internet o smartphones para poder encontrar nuevas interpretaciones en las historias que se cuentan. Este lector que interactúa, tiene que estar predispuesto a entrar en este juego lúdico. De una u otra manera también Cortázar (2013) tuvo presente a este "lector cómplice" al momento de escribir Rayuela. 
“[E]1 lector cómplice”: el autor de Rayuela, es un escritor que pide lectores cómplices; no quiere lectores pasivos, no quiere el lector que lee un libro y lo encuentra bueno o malo pero su apreciación crítica no va muy lejos y se limita simplemente a aprovechar todo lo que el libro le da o a sentirse indiferente si el libro no le gusta, pero sin tomar una participación más activa en el proceso mismo del libro. (p. 201).

La intención de Rayuela, es eliminar toda pasividad en la lectura en la medida en que sea posible y colocar al lector en una situación de intervención continua, página a página o capítulo a capítulo. (p. 202)

En Aqui está la música, el interactuante es el lector, aquí surge una interactividad no entre el escritor y el lector sino entre el lector y otro soporte; en este caso, lo musical puede ser atendido en una computadora con Internet, en un Smartphone, o si se diera el caso, en el disco donde se encuentra la canción o tema sugerido, si es que el lector lo tiene a la mano. Es decir vincula el soporte físico del libro con otro digital o físico. Podríamos estar hablando de que Aqui está la música es un libro que también forma parte de las narrativas transmedia, pues como define Scolari (2013), narrativa transmedia es "un tipo de relato donde la historia se despliega a través de múltiples medios y plataformas de comunicación, y en el cual una parte de los consumidores asume un rol activo" (p. 46).

Ante esto, podría existir el temor de si esto ayuda a los lectores o los aleja, Rodríguez (2011) plantea esa problemática y explica que:

Lo que choca hoy a muchos de la extensión de las TIC no es la tecnología en sí (al fin y al cabo, leer, escribir y publicar es toda una tecnología humana), sino el hecho de que no estamos familiarizados con las exigencias, competencias y posibilidades que abren las nuevas tecnologías.

Pero si se asume de este modo, no habría por qué asustarse, incluso el libro mismo y las prácticas que se dan a su alrededor pueden beneficiarse de las nuevas tecnologías, a condición de que visualicemos la manera de potenciar (no de acabar) los propósitos básicos de la práctica, que en el caso de la literatura consiste en la conformación y consolidación de una comunidad alrededor del hecho expresivo. (p. 15)

Este componente interactivo de Aqui está la música nos lleva entonces a ver al lector no como el lector unidireccional, sino a uno que va más allá de la experiencia impresa. El nuevo lector interactúa con el libro en sus diferentes soportes, digital o físico, y no solo eso, sino que sigue las historias que surgen de este hacia otros formatos, como el cine, comic, etc. Es decir, como plantea Scolari (2016), dentro de las nuevas narrativas transmedia se encuentra el translector.

Para interpretar ese universo narrativo el "lector" debe activar una serie de competencias y experiencias previas que no están presentes en la 
lectura tradicional. E1 lector transmedia es un lector multimodal que debe dominar diferentes lenguajes y sistemas semióticos, desde el escrito hasta el interactivo, pasando por el audiovisual en todas sus formas. En otras palabras: para comprender el universo de Star Wars, Juego de tronos, Harry Potter o de El Ministerio del Tiempo no basta saber leer. El translector debe moverse en una red textual compleja formada por piezas textuales de todo tipo y ser capaz de procesar una narrativa que, como una serpiente, zigzaguea entre diferentes medios y plataformas de comunicación. (pp. 181-182)

En ese caso, el lector o translector de Aqui está la música, no es ajeno a este tipo de interactividad o lecturas en diferentes medios y plataformas, y por eso, el juego lúdico que se propone es un elemento diferenciador con respecto a otras propuestas más tradicionales.

Entonces estos tres elementos intertextualidad, paratextualidad e interactividad, crearán este coro polifónico donde el lector interpretará y percibirá las historias de los cuentos, es decir, el mensaje, de otra manera, haciendo más dinámica la experiencia lectora.

\section{Conclusiones}

La cita como elemento intertextual ligado a lo musical en Aqui está la música interactúa con el nuevo lector o translector, a cuyas referencias musicales puede acceder más rápido a través del Internet y lograr así una nueva experiencia lectora de múltiples interpretaciones. Por otro lado, los distintos paratextos en Aqui está la música, en especial la nota de autor titulada "Instrucciones para musicalizar los cuentos", llevan al lector a otros niveles de comprensión e interacción con la obra. Niveles de mayor compresión y entendimiento de lo que el autor quiere llegar a transmitir con su obra y por otro lado lo interactivo pasa por un conocimiento que el lector debe tener, si no fuera el caso, el lector podrá tener la experiencia con el texto pero a un nivel básico. Entonces, los diferentes elementos intertextuales y paratextuales que contiene Aquí está la música, hacen que la interacción del lector con la obra sea más dinámica, y ese dialogo entre los diferentes elementos como las citas y referencias relacionadas a lo musical, hacen que la obra tenga una unidad temática.

Aqui está la música dependerá de un lector activo y participativo para que la experiencia total que el autor quiere transmitir en su obra pueda concretarse y se haga realidad. El tipo de interactividad que realiza en este caso el lector será de tipo monoparticipativa, pues no tiene un diálogo con el emisor o escritor sino que interactúa solo con la obra. El lector tiene que tener en este caso un tipo de saberes de búsqueda por las web; antes el lector tenía diccionarios o enciclopedias para poder descubrir lo que el autor o la historia querían contar, ahora 
el acceso a la Internet facilita esa labor, haciendo que pueda complementar la experiencia con videos, audios, textos complementarios, etc. En ese sentido, la utilización de las nuevas herramientas o soportes tecnológicos dentro de su vida cotidiana por parte de las personas, hace que la invitación a esta interacción entre el lector, el libro y lo sonoro esté acorde con este nuevo lector o translector.

\section{Notas}

1 El siguiente texto es parte de la tesis para optar el grado de magister en Escritura Creativa de la Universidad Nacional Mayor de San Marcos.

2 Manuscrito próximo a editarse.

\section{Referencias}

Aranibar, C. (2015). La novela más hermosa del mundo: escansión y música en Cervantes. Lima: Biblioteca Nacional del Perú.

Buarque, Ch. (2015). El hermano alemán. Madrid: Penguin Random House.

Caicedo, A. (2008). ¡ Que viva la música! Bogotá: Norma.

Carrillo, S. (2001, octubre). Julio Cortazar: Rayuela y el jazz. Rockdelux 189: Me, $M y$ self \& $I$. Recuperado de <http://www.rockdelux.com/opinion/p/julio-cortazar-rayuela-y-el-jazz.html> (14.07.2017).

Cortines Torres, J. (2012). "De Hoffmann al joven Galdós: cuatro cuentos musicales". En: Boletín de la Real Academia Sevillana de Buenas Letras, No: 40, pp. 489 - 506 Recuperado de https://idus.us.es/xmlui/handle/11441/14748 (14.06.2017)

Cortazar, J. (2013). Clases de Literatura. Madrid: Alfaguara.

Del Pozo, W. (Comp.). (2017). Gracias totales: Tributo narrativo a Soda Stereo. Lima: Ediciones Altazor.

Dylan, B. (2016). Letras completas: 1962 -2012. Barcelona: Malpaso.

Dylan, B. (2017, Junio 5). Discurso de aceptación del Premio Nobel, de Bob Dylan. Círculo de Poesía. Revista electrónica de literatura. Gustavo Osorio de Ita (tr.). Recuperado de http://circulodepoesia.com/2017/06/discurso-de-aceptaciondel-premio-nobel-de-bob-dylan/ (7.6.2017)

Echeverry Hurtado, M. (2013). Relaciones intertextuales entre música y literatura en la novela "Qué viva la música!" de Andrés Caicedo. (Tesis de maestría). Buenos Aires: Universidad de Buenos Aires. Tesis de maestría de literaturas española y latinoamericana. Recuperado de http://repositorio.filo.uba.ar/bitstream/ handle/filodigital/2038/uba_ffyl_t_2013_887810.pdf?sequence=1\&isAllowed=y (12.07.2017)

Eco, U. (1984). Apostillas a El nombre de la rosa. Rosa Premat (Tr.). Anàlisi Quaderns 
de comunicación i cultura. Nro. 9, 5 - 32. Universitat Autònoma de Barcelona. Recuperado de http://www.raco.cat/index.php/Analisi/article/viewFile/41264../88267 (7.06.2017)

Ferreira, C. (1989, Primavera). Sobre Alfredo Bryce Echenique: La última mudanza de Felipe Carrillo. Inti: Revista de literatura hispánica: No. 29, Article 40. Recuperado de http://digitalcommons.providence.edu/inti/vol1/iss29/40 $(4 / 10 / 2017)$

Genette, G. (1989). Palimpsestos: La literatura en segundo grado. Fernádez Prieto, Celia (Tr.). Madrid: Taurus.

Larrea, E. (2013, setiembre 26). La criolla inmortal de Vargas Llosa. La Mula. Recuperado de https://lamula.pe/2013/09/26/la-criolla-inmortal-de-vargas-llosa/ enriquelarrea/ (14.07.2017)

Lévy, P. (2007). Cibercultura: Informe al Consejo de Europa. Barcelona: Anthropos Editorial, Universidad Autónoma Metropolitana.

Navarro Martínez, E. (2003, abril). Novelas con banda sonora: La música como recurso técnico en algunas obras de la narrativa española actual. Tonos digital: Revista Electrónica de estudios filológicos. Nro. 5. Universidad de Murcia. Recuperado de https://www.um.es/tonosdigital/znum5/estudios/I-Novelassonora. htm (7.06.2017)

Peri Rossi, C. (1997). Génesis de un cuento. El cuento hispanoamericano del siglo XX. Teoría y práctica. Valcarcel, Eva. (Ed.), 283-300. Universidade da Coruña. Recuperado de http://ruc.udc.es/dspace/bitstream/handle/2183/9736/CC_38_ art_20.pdf?sequence $=1$ (21.06.2017)

Poe, E. (1846). Método de composición. Recuperado de http://ciudadseva.com/texto/ metodo-de-composicion/ (3.04.2017)

Rancière, J. (2011). El malestar de la estética. Buenos Aires: Capital intelectual.

Real Academia Española. (2014). Diccionario de la lengua española (23.a ed.). Recuperado de http://dle.rae.es/ (17/10/2017)

Rilke, R. ([1929], 2006). Cartas a un joven poeta. Madrid: Alianza Editorial.

Rodríguez, J. (2009, enero-junio). Sueños digitales de un escritor: la convergencia digital al servicio del ejercicio literario. Signo y Pensamiento, Vol. XXVIII, Núm. 54, 131-143. Colombia: Pontificia Universidad Javeriana. Recuperado de http://www.scielo.org.co/pdf/signo/v28n54/v28n54a09.pdf (3/10/2017)

Rodríguez, J. (Ed.) (2011). Narratopedia. Bogotá: Editorial Pontificia Universidad Javeriana, (Colección estudios literarios).

Scolari, C. (2013). Narrativa transmedia: Cuando todos los medios cuentan. Barcelona: Deusto.

Scolari, C. (2016). El translector. Lectura y narrativas transmedia en la nueva ecología de 
la comunicación. La lectura en España. Informe 2017, 175-186. Madrid. Federación de Gremios de Editores de España. Recuperado de http://www.fge.es/ lalectura/docs/Carlos_A_Scolari\%20_175-186.pdf (3/10/2017) 